\title{
CHRONICLES OF MEDICAL HISTORY IN AFRICA PIONEERS OF HEART SURGERY: FROM ARISTOTLE TO GRILLO
}

\author{
S.O. Michael \\ Department of Pharmacology and Therapeutics, University of Ibadan, Ibadan.
}

The history of diseases of the circulatory system forms one of the most interesting chapters in medical history. There is no organ in the body that has mystified and fascinated man like the Heart. Fascination with the heart goes far beyond that of clinical medicine. From the historical perspective of art, customs, literature, philosophy, religion, and science, the heart has represented the seat of the soul and the wellsprings of life itself. Such reverence also meant that the heart was long considered a surgical untouchable. As with every discovery or advancement in knowledge, the evolution of cardiac surgery is intimately connected with the evolution of human thought.

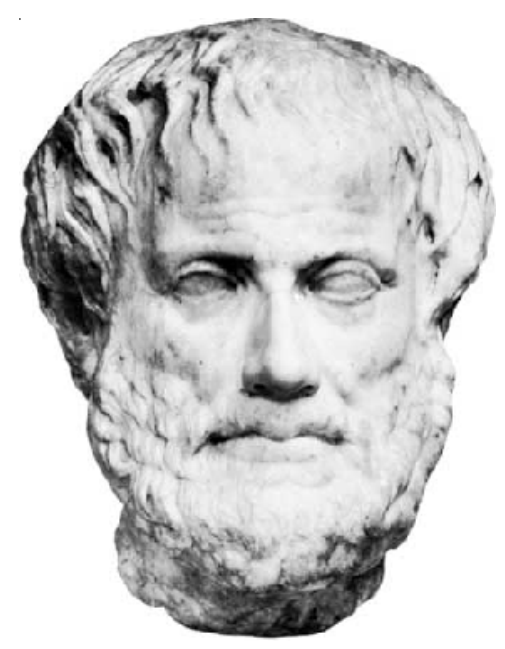

Aristotle

Aristotle (384-322 вс): Greek philosopher and scientist, shares with Plato and Socrates the distinction of being the most famous of ancient philosophers. Aristotle was born at Stagira, in Macedonia, the son of a physician to the royal court. At the age of 17 , he went to Athens to study at Plato's Academy. Trained as a physician he brought to his philosophy a due respect for facts and analytical method. His method of logic started the movement of thought and reasoning that eventually led to the abandonment of superstition and metaphysics. However, Aristotle had thought that the heart is the central abode of life, the mind, and the soul, the hearth from which emanate generative animal heat, something different from sterile, elemental fire, and that from the heart the blood and blood vessels are derived.

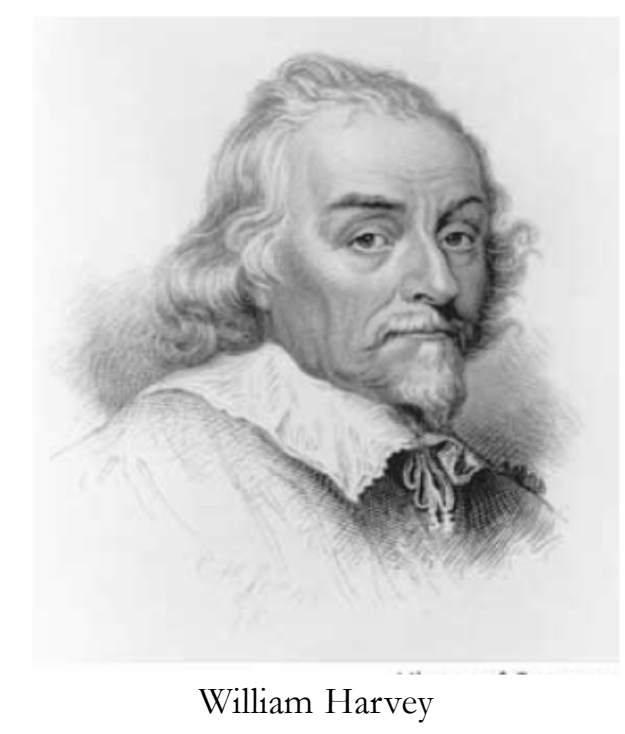

William Harvey (1578-1657), transferred this Aristotelian primacy to the blood, to which the heart is only of use as a pump to keep it in motion. Harvey was the first man to revive a quiescent heart by perfusion (wetting it with saliva). Harvey revived the ancient belief that "the soul is in the blood". He knew, together with Galen, of the contractile power of the heart muscle and that the excised heart will beat outside the body, but could not explain the simultaneous beating of the auricles. William Harvey undoubtedly was the greatest name in $17^{\text {th }}$ century medicine. In the year 1628, Harvey published his classic work De motu cordis et sangunis, which gave birth to scientific cardiology. The greatest obstacle to further exploits into surgical repair of the body and organ transplants was the belief that the soul (or spirit) and the body were one and the same thing. This widespread belief, that the intangible spirit of man was the seat of life, hindered progress in the scientific study of living systems in general and man in particular. It was generally believed that nothing could be done to restore bodily disorders since they originated from the spirit. A paradigm shift was needed, and this was what Rene Descartes brought with his philosophy of mind-body duality.

René Descartes (1596-1650): French philosopher, scientist, and mathematician, sometimes called the father of modern philosophy.

Born in La Haye, Touraine (a region and former province of France), Descartes was the son of a minor 
nobleman and belonged to a family that had produced a number of learned men. At the age of eight he was enrolled in the Jesuit school of La Flèche in Anjou, where he remained for eight years. Besides the usual classical studies, Descartes received instruction in mathematics and in Scholastic philosophy.

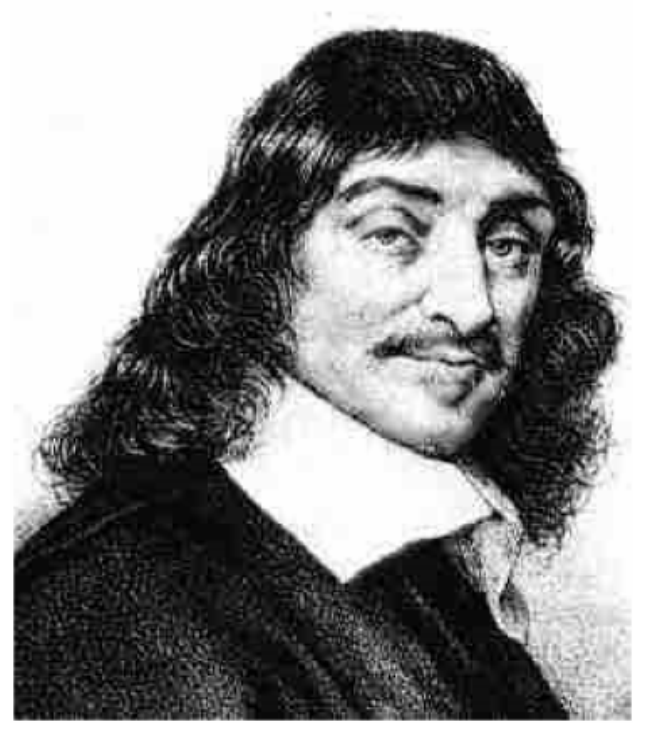

Rene Descartes

Although philosophers have written about mental phenomena since ancient times, the philosophy of mind did not gain much attention until the work René Descartes in the 17th century. Descartes's work represented a turning point in thinking about mind by making a strong distinction between bodies and minds, or the physical and the mental. This duality between mind and body, known as Cartesian dualism, had posed significant problems for philosophy since antiquity. Descartes believed there are two basic kinds of things in the world, a belief known as substance dualism. For Descartes, the principles of existence for these two groups of things_-bodies and minds_-are completely different from one another: Bodies exist by being extended in space, while minds exist by being conscious. According to Descartes, nothing can be done to give a body thought and consciousness. No matter how we shape a body or combine it with other bodies, we cannot turn the body into a mind; a thing that is conscious, because being conscious is not a way of being extended. Thus by manipulating the body, the soul or spirit was in no way affected. With this change in the way the body and the mind are related anatomist moved from the cautious dissection of animals (as done by Galen) to dissection of humans as well illustrated by André Vesalius. Perhaps human anatomy remains the greatest single advancement in the history of medicine. The doors were open for advancement in every specialty of surgery and organ transplant. Many were to become the great pioneers of open heart surgery; men who entered the realm previously believed to have housed the spirit and life of man.

Open Heart Surgery: The doctrine of the heart as an automatic mechanism through contractile impulses passing from muscle-cell to muscle-cell was the work of Gaskell and Engelman (1843-1909). Engelmann experimented with dissected frog hearts in 1875 and demonstrated that heart contractions originate within the heart muscle and not as the result of an external nerve stimulus. The heart is a muscular organ that rhythmically contracts to force blood around the body of an animal with a circulatory system. Annelid worms and some other invertebrates have simple hearts consisting of thickened sections of main blood vessels that pulse regularly. An earthworm has ten such hearts. Vertebrates have one heart. The fish heart has two chambers- the thin-walled atrium (once called the auricle) that expands to receive blood, and the thickwalled ventricle which pumps it out. Amphibians and most reptiles have two atria and one ventricle; birds and mammals have two atria and two ventricles. The beating of the heart is controlled by the autonomic nervous system, and by hormones.

Daniel Hale Williams (1858-1931): A black physician and surgical pioneer who performed the first successful heart surgery. Born in Hollidaysburg, Pennsylvania, Williams started work as an apprentice shoemaker at age 12 . He worked his way through Janesville Classical Academy in Janesville, Wisconsin, as a barber and bass violinist. In 1893 he received a medical degree from Chicago Medical College, now part of Northwestern University. After serving his internship at Mercy Hospital in Chicago, Williams was appointed surgeon at the city's South Side Dispensary and instructor of anatomy at Northwestern University in 1894. He was also named physician for the Protestant Orphan Asylum. Williams achieved widespread fame after performing the first successful open-heart surgery on record. In 1897 a patient who had been in a street fight was brought to Provident Hospital with a deep knife wound in his chest. Williams opened the man's chest and observed that the pericardium, the sac surrounding the heart, had been punctured by the knife. He repaired the tear, closed the chest, and the patient recovered fully. Surgery to correct some congenital defects involving blood vessels also laid the foundations for surgery on the heart itself.

One of the first surgeons to use improved techniques to gain access to the heart was Dr. Dwight Harken, a young U.S. Army surgeon. Many of Harken's patients were young soldiers evacuated from the European front with shell fragments and bullets lodged inside 
their hearts. To leave the shrapnel in was dangerous, but removing it was almost surely fatal. Harken began operating on animals, trying to develop a technique that would allow him to cut into the wall of a still beating heart, insert a finger, locate the shrapnel and remove it. All of his first 14 animal subjects died. Of the second group of 14, half died. Of the third group of 14 , only 2 died. Harken felt ready to try the technique on humans. All of his patients survived, proving that the human heart could be operated upon. At about the same time Dr. Charles Bailey independently reported a daring procedure to correct mitral stenosis. In 1938 American surgeon Robert Gross performed the first successful surgery to treat an open ductus arteriosus, tying the vessel closed with thread. In 1944 Gross and Swedish surgeon Clarence Crafoord each performed successful surgery for coarctation of the aorta. The same year, American surgeon Alfred Blalock and surgical assistant Vivien Thomas performed the first successful operation to correct tetralogy of Fallot.

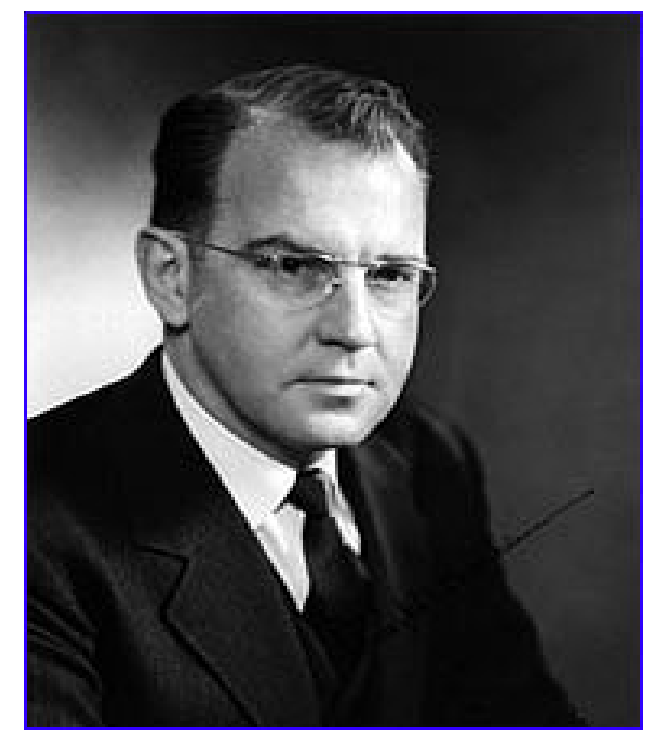

Daniel Hale Williams

Dr. Vivien Theodore Thomas (August 29, 1910 November 26, 1985) was an African-American surgical technician who developed the procedures used to treat blue baby syndrome in the 1940s. He was an assistant to Alfred Blalock in Blalock's experimental animal laboratory at Vanderbilt University in Nashville, Tennessee and later at the Johns Hopkins University in Baltimore, Maryland. Without any education past high school, Thomas rose above poverty and racism to become a cardiac surgery pioneer and a teacher of operative techniques to many of the country's most prominent surgeons. Vivien Thomas was the first African American without a doctorate degree to perform open heart surgery on a white patient in the United States.
Initial results of heart surgery were disastrous. Cardiac surgeons frantically sought ways of opening the heart without the patient bleeding to death. At the University of Minnesota, a young Canadian surgeon named Dr. Bill Bigelow came up with the first workable, if highly bizarre, answer. He had noticed how hibernating animals, like ground hogs, survived the cold Canadian winters. Their hearts beat slower, allowing them to survive for months without food. Wondering if cold might be the key to operating inside the heart, Bigelow began animal experiments and found that when dogs were cooled, open heart surgery could be done for long periods-much longer than four minutes-and they didn't die. He showed that at lower temperatures, the tissues of the body and brain didn't need as much oxygen, and could survive without oxygenated blood for longer. On September 2, 1952, two University of Minnesota surgeons, Dr. Walton Lillehei and Dr. John Lewis, attempted the first open heart surgery on a five-year-old girl who had been born with a hole in her heart. Anaesthetized to stop her shivering, the girl was cooled by a special blanket until her body temperature reached 81 degrees F. At this temperature, she could survive without a pumping heart for ten minutes, not four. Clamping the inflow to her heart so that it is emptied of blood, Lillehei and Lewis cut open her heart, which was still slowly beating, and quickly sewed up the hole. With the repaired heart working properly for the first time in her life, the girl was then immersed in a bath of warm water to bring her body temperature back to normal. The operation was a success. The "hypothermic approach" became very successful in treating small heart defects. But all too often, surgeons opened hearts to find more complex defects_-defects that couldn't be repaired in 10 minutes.

John Gibbon (1903-1973): Introduced the heart-lung machine, a device to oxygenate and pump blood during surgery on the heart. This device introduced in 1953 is considered the greatest leap forward in open heart surgery. This invention made open-heart surgery - with the heart stopped for the duration of the operationpossible. It led to now-routine surgical techniques such as valve replacement, correction of congenital defects, and bypass surgery.

Christiaan Neethling Barnard (1922-2001): Born at Beaufort West, South Africa. Dr. Christiaan Barnard performed the world's first human heart transplant on 3 December 1967. The patient, 53-year-old dentist Louis Washkansky, was given the heart of a 25-yearold auto crash victim named Denise Darvall. Washkansky died from infection 18 days later, but the transplant made Barnard one of the world's most fa- 
mous surgeons. He died in 2001 while on vacation in Cyprus, following an asthma attack.

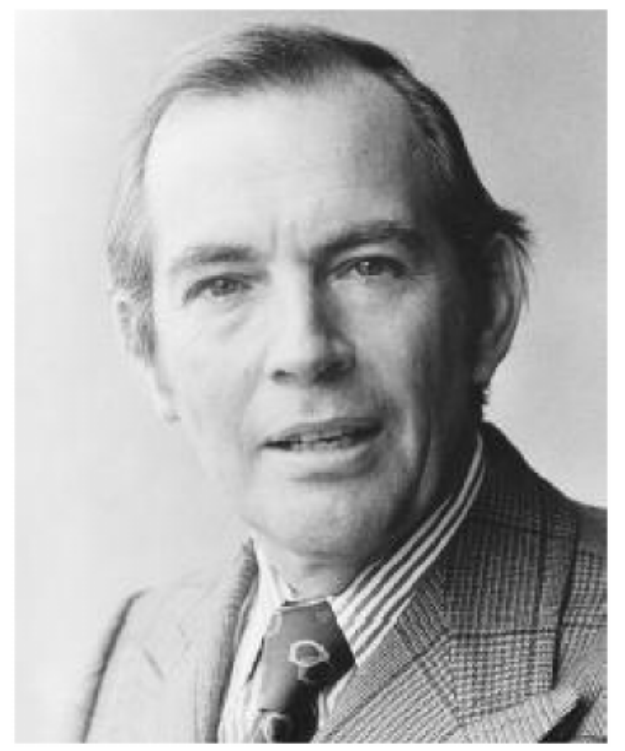

Christiaan Neethling Barnard

But these surgical triumphs proved short-lived. Patients began dying of either rejection or infection. By 1971,146 of the first 170 heart transplant recipients in the United States were dead. Only one American surgeon would continue, Dr. Norman Shumway. Throughout the 1970's, he built a team of scientists and doctors to tackle the complex biological problem of tissue rejection in a careful, scientific manner. His team devised a way of spotting rejection attacks, by feeding a catheter into the heart and removing a piece of heart muscle for examination. Only when signs of rejection were seen were doses of the dangerous immuno-suppressive drugs increased. Shumway benefited from a chance discovery made in another part of the world. In the soil of Norway's Hardaanger fjord, a fungus was found which contained a compound that would revolutionize transplant surgery. The substance, called cyclosporin, appeared to have exquisite immuno-suppressant properties_-controlling organ rejection without knocking out all resistance to infection. In the hands of Dr. Shumway, cyclosporin transformed the picture for heart transplant recipients. Hospitals around the world began to reopen their heart transplant units and more and more patients survived the procedures. In 1994, Dr. Randas Batista of Brazil devised a radical new surgical technique to treat a common form of heart failure for people with enlarged hearts. Batista's idea was to cut a swath out of the left ventricle and sew the chamber back together, thereby reducing its size and increasing its efficiency. Heart research has had a very long and colorful history and almost all the superstitious beliefs surrounding the once mystical organ have been dispelled. The future looks even brighter with developments in xenotransplantation, tissue regeneration, full organ culture, and artificial hearts.

The Nobel Prize: It was appropriate that the 1956 Nobel Prize in medicine was awarded jointly to three pioneers in heart research: Drs. André Cournand, Dickinson W. Richards, and Werner Forssmann, for their discoveries concerning heart catherization and pathological changes in the circulatory system. The latter was courageous enough, back in 1929, to push a long, pliable thin tube through a vein in his right arm into the right-sided chambers of his heart. Through this tube he could measure blood pressure fluctuation in the heart and draw out blood samples for oxygen analysis. Drs. Cournand and Richards later improved the technique and applied it to a more accurate diagnostic appraisal of the diseased or congenitally malformed heart which had until then been impossible.

Open heart surgery in Nigeria: From the early 1940s the field of cardiology slowly evolved and diseases of the heart requiring surgical intervention where identified in Nigerians. The establishment of the cardiac registry in 1964 in Ibadan revealed many types of cardiac diseases including those requiring surgical intervention. Congenital heart diseases topped the list and those affected died helplessly unless they were able to seek surgical repair outside the country. A historic landmark was made at the University of Nigeria Teaching Hospital (UNTH), Enugu in January 1974 when the first open heart surgery was performed. The team of surgeons that carried out this historic surgery included Yacoub M (Egyptian-British citizen), Prof Fabian Udekwu, Nwafor DC, Anyawu CH, and others. The first patient operated upon was a 19 year old man who presented with a history of dyspnoea, chest pains, fatigue and was in heart failure. The diagnosis was that of aneurismal PDA. Resection of the aneurysm was carried out under a bypass that lasted 90 minutes. The patient survived and the heart failure was reversed. Between Jan 1974 and March 1980 seven patients aged between 15 and 25 years were offered open heart surgery at UNTH Enugu. Four were females and three were males. Professor Martin Aghaji's team remains at the forefront of open heart surgery at the Enugu center.

In January 1976 a group of surgeons comprising Grillo IA, Osinowo O, Adebonojo SA, and Adebo AO started surgical interventions for arteriovascular diseases. The young surgeon Oluwole Adebo developed keen interest in arteriovascuscular diseases and in 1982 reported the experience in vascular surgery at Ibadan. The spectrum of cases he reported were thoracic aneurysms, coactation of the thoracic aorta, abdominal aortic aneurysm, aorto-ilio-femoral occlusive disease, 
arterio-venous fistula, femoral aneurysms, and others, a total of 40 cases. In December 19, 1978 history was made in Ibadan when Professor Grillo led the team that performed the first open heart surgery at Ibadan. The team comprised three other surgeons (Adebonojo AA, Osinowo O, and Adebo AO), two anesthesiologists (Akinyemi $\mathrm{O}$ and Famewo $\mathrm{CE}$ ), a young cardiologist (Falase AO, who went on to a very distinguished career as a cardiologist and administrator), a cardiopulmonary pump technician (Mr Osanyintuyi SO), and a theater nurse (Mrs Omotosho). Between December 1978 and December 1980 five patients aged 1417 years underwent open heart surgery at the University College Hospital, Ibadan, for various congenital cardiac defects. There were four males and one female. University College Hospital, Ibadan, joined the league of prestigious hospitals where open heart surgery is carried out. The Institute of Cardiology at Abidjan and the Kenyatta National Hospital at Nairobi also achieved similar feats.

Surgery as an art and science shows us the beauty of teamwork. No surgeon is an island and the achievements of the past are stories of successful teamwork. Prof Grillo in his publication mentioned the collaborations among departments that made the first open heart surgery possible. In addition it is also very clear that the team that performed the first heart surgery was united in every possible way. Every member of the team made equal contributions. Sadly the same cannot be said today, more and more researchers are comfortable doing it alone. The rights over priority in publications have torn teams apart. This trend must be reversed. One star can be visible in the heavens, but billions of stars light up the sky in beautiful splendor. There should not be competition but rather collaboration; the sky has more than enough room for all the stars. Science has advanced beyond the capacity of the individual; this is the era of sincere and concerted team effort. An adage has it that if one wants to travel fast he or she should travel alone but those who wish to go very far should go together. 'Togetherness' is the magic ingredient of all great achievements. The Department of Surgery, University College Hospital Ibadan, is currently being steered in a positive direction by the wise and amiable Prof. Victor Adegboye.

Grillo IA: Isaac Adetayo Grillo was born in Lagos, Nigeria, on January 15, 1931. As a young boy he always imagined himself becoming a great pioneer in the medical sciences. After his primary and secondary education in Nigeria he won a foreign student's scholarship to McPherson College in the United States of America which he attended between 1952 and 1955. He graduated BSc Biology/Chemistry and BA Edu- cation cum laude after seven semesters, in 1955 . He sailed through Kensas University Medical School and graduated Doctor of Medicine in 1960, the only black graduate in a class of 99 doctors. He did his internship at the Menorah Medical Center Kensas City, Missouri, between 1960 and 1961. Between 1961 and 67 he trained at the postgraduate level at Homer G. Philips Hospital, Missouri, Alemenda County Hospital California, and Olive view Hospital, California as a Thoracic Surgeon. He returned to Nigeria in 1968 where he served as Field Lieutenant Colonel in the Nigeria Civil War in 1969. He joined the University of Ibadan and the University College Hospital in 1968 as Lecturer and Consultant. He was assistant professor between 1971 and 1978. He rose to the rank of Professor in 1978 and he was Head of the Department of Surgery between 1985 and 1988. From 1988 to 1990, he was Senior Consultant, Cardiothoracic Surgery Unit of the King Fahd Central Hospital at Saudi Arabia.

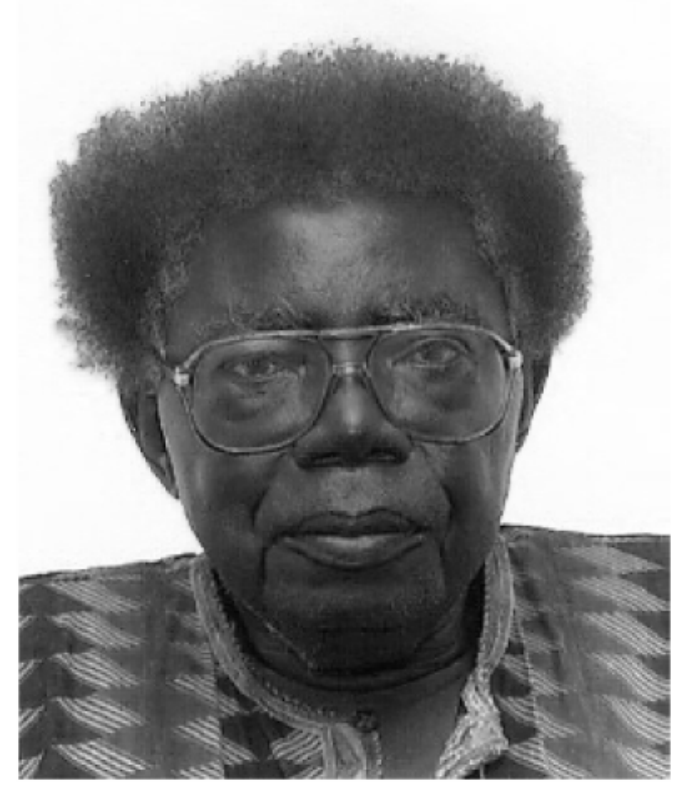

Isaac Adetayo Grillo

He obtained the Doctor of Science degree in 1987. He is a man of many scholarship awards, Fellowships, citations in "who is who", and achievements too numerous to list. He was and still is a very good mentor to those who trained the current generation of cardiovascular surgeons. His publications are found in journals of four continents of the World. His most recent publication is a book titled "Medical/Surgical care of Male American prisoners (Dec 2009)". In December 1978 he led the team of surgeons that performed the first open heart surgery in Ibadan, thus fulfilling his childhood dream of becoming a medical pioneer whose footsteps would never be erased from the sands of the history of cardiovascular surgery. 
Like professor Grillo most of us have personal dreams and ambitions that we hope to fulfill. Many, however, are unable to give what it takes to be significantly outstanding. Life becomes an experience tolerated and survived, but God put in everyone the potential to initiate great things and eventually to transform ourselves and nation positively. To find gold one must dig deep, to become diamond carbon (a common element) must pass through the furnace. The problems are all starring at us- poor electricity, mal-functioning equipment, crumbling infrastructure, poor work ethics, non-functioning private sector, deteriorating morals at the individual level, etc. Prof O.O. Akinkugbe once said that there was a time that one found it difficult to find parking space in the hospital at $7.00 \mathrm{pm}$ because the offices were full of researchers doing quality research and aiming for the first position in the World. There was a time that foreigners chose to earn their degrees in Nigerian Universities. We must bring those days back. The responsibility falls on the individual and not the government. All it takes is for people to take the initiative, to start and make progress despite all hindrances. A story like that of Prof Isaac Adetayo Grillo may take less than 30 minutes to read but a life like his would take a lifetime of extreme determination, focus, very hard work, and relentless pursuit. A life of significance is desired by all, but it is not for the faint-hearted. The opposition is stiff for those whom history remembers but, like Dr Oluyombo Awojobi has proven; the human spirit is far above any challenge, far above any obstacle. Nothing is impossible to the individual who believes and there is no situation that cannot be reversed or improved upon.
To the faint-hearted you can contribute by staying out of the way and cheering those who have taken the bull by the horns, those on a path of self-actualization and national/international significance; those who have taken the initiative to restore the greatness of this nation and her people. This is the only other option because the current tide of restoration cannot be stopped.

\section{REFRENCES}

1. Microsoft (®) Encarta ( 2007 . (C) 1993-2006 Microsoft Corporation.

2. Fielding H. Garrison. An introduction to the history of medicine. W.B. Saunders Company, fourth edition, 1929.

3. John C. Eze, and Ndubueze Ezemba, OpenHeart Surgery in Nigeria Indications and Challenges. Guest editorial. Tex Heart Inst J. 2007; 34(1): 8-10.

4. http://en.wikipedia.org/wiki/Vivien_Thomas

5. Anyawu $\mathbf{C H}$, et al. initial experience with open heart surgery in Nigeria. Tropical Cardiology, 1982; 8: 120-128

6. Adebonojo SA, Grillo IA, et al. Initial experience with open heart surgery at the University College hospital, Ibadan, Nigeria. Tropical Cardiology, 1981; 7; 49-54

7. Adebo OA, Osinowo O, Adebonojo SA, Grillo IA. Vascular surgery at Ibadan, experience at the university College Hospital, Ibadan. Tropical Cardiology, 1982; 8; 113-121

\section{MEDICAL DISCOVERIES - QUIZ QUESTIONS}

1. Who was the founder of Homoeopathy?

2. Which Indian doctor discovered a cure for Kala-azar (Visceral Leishmaniasis)?

3. Who first isolated bacilli?

4. Who discovered X-rays?

5. Who discovered in 1720 , an instrument for measuring body temperature?

6. Who discovered the importance of vaccination against Small-Pox?

7. Who discovered the Malaria Parasite?

8. Who is regarded as the father of Psycho analysis?

9. Who invented the first man-made insecticide, D.D.T.?

10. Who discovered the 'benefits of chloroform surgery'?

11. In 1816, an instrument for listening to the sound made by the heart and lungs was discovered. What was it and who was the discoverer?

12. Who discovered the Anti-Rabies Vaccine in 1882?

13. Who invented the Bifocal lens?

14. When was the Iron-Lung invented?

15. What did J.B. Priestley discover in 1774 ?

16. Which operation was pioneered by Dr. Christian Barnard in 1967?

17. Who discovered the cure for scurvy?

18. Who invented the Contact-Lenses?

19. What was discovered by Frederick Banting in 1932 which gave relief to sufferers of diabetes?

20. What discovery by Madam Curie led to a breakthrough in the fight against the dreaded disease, cancer? 